\title{
Integrated citrus thrips control reduces secondary pests
}

\author{
Beth Grafton-Cardwell $\sqcup$ Ashley Eller $\quad$ Neil O'Connell
}

\begin{abstract}
Citrus growers are very concerned about scarring of the rind caused by early-season pests such as citrus thrips, katydid and various Lepidopterous larvae because heavily scarred fruit is downgraded in the packing house. Citrus growers who use a broadspectrum pesticide program for early-season pests experience problems with pest resurgence and pesticide resistance, but generally have low levels of fruit scarring. Growers who use both selective pesticides and natural enemies have fewer secondary pest outbreaks of citrus red mite, but don't always effectively control citrus thrips scarring.
\end{abstract}

During the 1992 and 1993 field seasons, we monitored citrus arthropod pests and natural enemies in the San Joaquin Valley. This monitoring provided important information about the consequences of various Integrated Pest Management (IPM) options used by citrus growers and aided our education program. We monitored 12 different citrus orchards in eastern Fresno, Tulare and Kern counties ranging in size from 8 to 25 acres. Insects (citrus thrips, fruit-tree leafroller, citrus cutworm, soft scale, armored scale and wasp parasites) and mites (citrus red mite and predatory mites) were sampled throughout the citrus growing season on a twice-weekly, weekly or monthly basis and the population trends were reported in a newsletter. Through this program we observed the seasonal trends in arthropod populations, their responses to pesticide applications and their interactions with predators and parasites.

We established the project with 10 to 12 pest control advisors (PCAs).

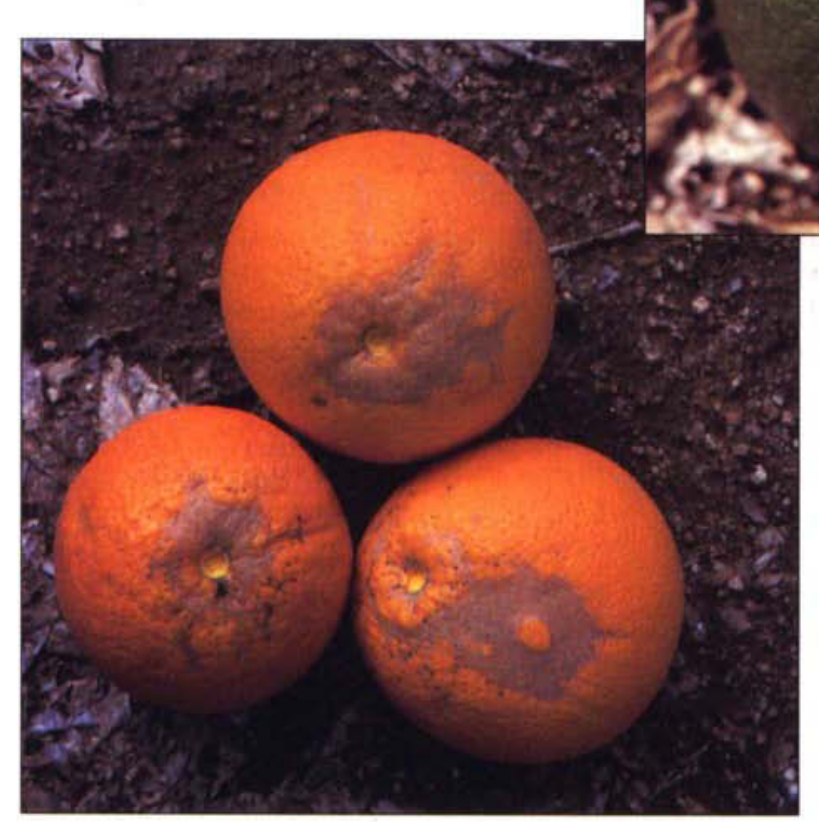

A Green fruit with citrus thrips damage. Scarring damage generally occurs early in the season (April to June) when the fruit is first forming.

4 These mature oranges have been scarred by citrus thrips. Scarred fruit is downgraded in the packing house.

These advisors worked with growers who initially planned to use either a selective pesticide approach or a broad-spectrum pesticide approach to citrus-pest management in the orchards we were monitoring.

The selective approach used a combination of selective pesticides and natural enemies to control pests. Selective pesticides are less toxic to the beneficial insects and mites than to the pests when used appropriately. In citrus, these pesticides include microbials (Dipel and Javelin), botanicals (Sabadilla and Ryania), miticides (Vendex and Omite) and petroleum oils. Selective pesticides can work with natural enemies such as the predatory mite Euseius tularensis and the parasitic wasps Aphytis melinus and Comperiella bifasciata to control pests over long periods of time.

However, selective insecticides are sometimes not as effective as broadspectrum pesticides in reducing pest populations. The broad-spectrum approach depends entirely on these pes- ticides. Broad-spectrum pesticides applied to citrus include a pyrethroid insecticide (Baythroid), organophosphate insecticides (Lorsban, Supracide, Dibrom and Cygon) and carbamate insecticides (Carzol, Lannate and Sevin).

Growers who use these pesticides attempt to have "clean" orchards with few pests and expect to eliminate insect damage to the fruit. However, a single application of a broad-spectrum pesticide may not control pests through the entire season. When pests do reappear, there are fewer natural enemies to combat them. Consequently the pest populations often resurge and more pesticide applications are needed. In addition, broadspectrum pesticides are becoming less effective because pests such as citrus thrips and armored scale are developing resistance to many of them. Because of these problems, citrus growers are becoming more interested in using selective insecticides, acaricides and natural enemies to obtain longterm control of pests. 
Citrus growers are especially concerned about scarring of the rind of the fruit caused by insects and mites because scarred fruit is downgraded in the packing house. San Joaquin Valley growers apply pesticides in the spring to protect their navel and Valencia oranges and sell them in the fresh fruit market the following winter and summer. If scarring is severe, the fruit will be downgraded and processed as juice instead of fresh fruit, and the grower will not recover the cost of pest management. Scarring damage generally occurs early in the season (April to June) when the fruit is first forming. The insect pests that cause this type of damage include various Lepidoptera such as citrus cutworm (Egira [Xylomyges] curialis) and fruit-tree leafroller (Archips argyrospilus), citrus thrips (Scirtothrips citri) and katydid (Scudderia furcata). Scarring damage ranges from a shallow ring around the calyx to deep irregular chewed areas; this type of damage is retained as the fruit matures. Citrus red mite (Panonychus citri) is also present early in the season. The damage they cause to the fruit looks like silvering or stippling; however, as the fruit matures the stippling or silvering usually disappears.

This article discusses the trends in early-season densities of citrus thrips, citrus red mite and predatory mites and their responses to the two different management programs observed. Katydid and Lepidoptera were generally found in low numbers in the sampled orchards during 1992 and 1993.

\section{Arthropod phenology}

Citrus thrips is a multigenerational pest that is present on the crop throughout the growing season. In March the over-wintering eggs hatch and immature thrips begin feeding on the tender leaves and newly developed fruit. From petal fall until the fruit reaches $25 \mathrm{~mm}$ in diameter, the fruit is most susceptible to damage. Cosmetic damage to the fruit can be quite extensive, leaving permanent scabby silvery scars on the rind.

To estimate the citrus thrips population density, we examined 5 outside fruit per tree and 5 trees in each quadrant of each orchard (100 fruit per orchard), starting at least 3 trees in from

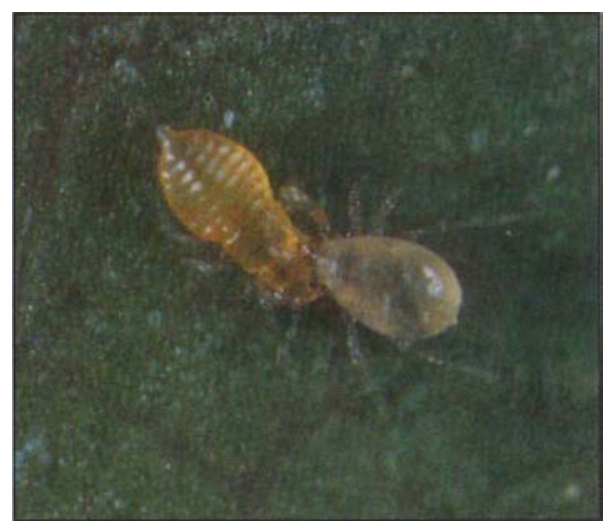

Euseius tularensis preys upon a second instar citrus thrips.

the outside edge. We removed new fruit and looked for live immature citrus thrips on the calyx and on the fruit. We recorded the number of fruit infested with one or more live immature thrips out of 100 fruit to obtain the percentage of fruit infested.

We also sampled each orchard for thrips scarring of the green fruit by selecting 20 trees ( 5 from each quadrant of the orchard) during August or September. We examined all of the outside fruit on these trees in the range of 1.5 to 6 feet from the ground. The fruit was rated according to the extent of scarring: 0 , no visible damage; 1 or 2 , minimal scarring and may be acceptable in the choice grades; 3 or 4 , severe scarring and likely to be downgraded from fancy to choice or juice by the packing house.

The predatory mite found most often in citrus is Euseius tularensis, a generalist feeder that nourishes itself with pollen, leaf sap and a variety of small arthropods, including citrus thrips and citrus red mite. This predatory mite has the ability to build up natural populations that are quite large, depending on the orchard conditions and available food sources. The treatment thresholds for citrus thrips and citrus red mite are raised in the presence of the predatory mite because of its effective feeding on these pests. Monitoring for the predatory mite was done weekly by sampling one 5-leaf terminal of 1-year-old foliage from 5 trees randomly selected in the interior of each quadrant of the block (100 leaves per orchard). The number of adult female predatory mites per leaf was counted and recorded.

Citrus red mite is usually present in the field early in the growing season.
Feeding by citrus red mite causes the fruit and leaves to become stippled or silvered in appearance. High densities of citrus red mite can develop in water-stressed conditions. We monitored citrus red mite throughout the growing season by sampling individual leaves per tree chosen at random from the 4 quadrants of the orchard (100 leaves per orchard). The number of adult female mites per leaf was recorded.

\section{Broad-spectrum approach}

Figure 1 shows the densities of citrus red mite, citrus thrips and predatory mites in the six sites that used a broad-spectrum insecticide approach to citrus thrips control during 1992. In late April, shortly after petal fall, we observed emergence of immature citrus thrips on the fruit; the percentage of infested fruit ranged from 3 to $17 \%$. UC IPM Publications 15 and 3303 suggest 5\% navel fruit infested with immature citrus thrips as a treatment threshold when predatory mites are absent or their densities are low. Growers in Sites 3, 6 and 12 did not wait for this threshold to be reached to apply a broad-spectrum pesticide. In Site 6, a pre-petal fall, night-time treatment of Lorsban was applied. Growers in Sites 7, 10 and 11 treated with insecticides shortly after petal fall when infestation of fruit had reached or surpassed the threshold of $5 \%$.

The infestation of fruit with citrus thrips can change from $0 \%$ to more than $10 \%$ in 3 to 4 days. For this reason, growers using broad-spectrum pesticides tend to spray as soon as petal fall is declared. Growers cannot spray these insecticides before petal fall during the day because of the hazard that broad-spectrum insecticides present to honey bees. The post-petal fall pesticide applications for citrus thrips included Carzol alone and mixtures of Carzol plus either Lorsban, Cygon or Lannate. Many growers believe that a combination of Carzol for residual kill and Lorsban, Cygon or Lannate for knockdown is needed to control citrus thrips.

In Sites 6 and 11, one or two broadspectrum treatments applied close to petal fall reduced citrus thrips to undetectable levels, and their densities 


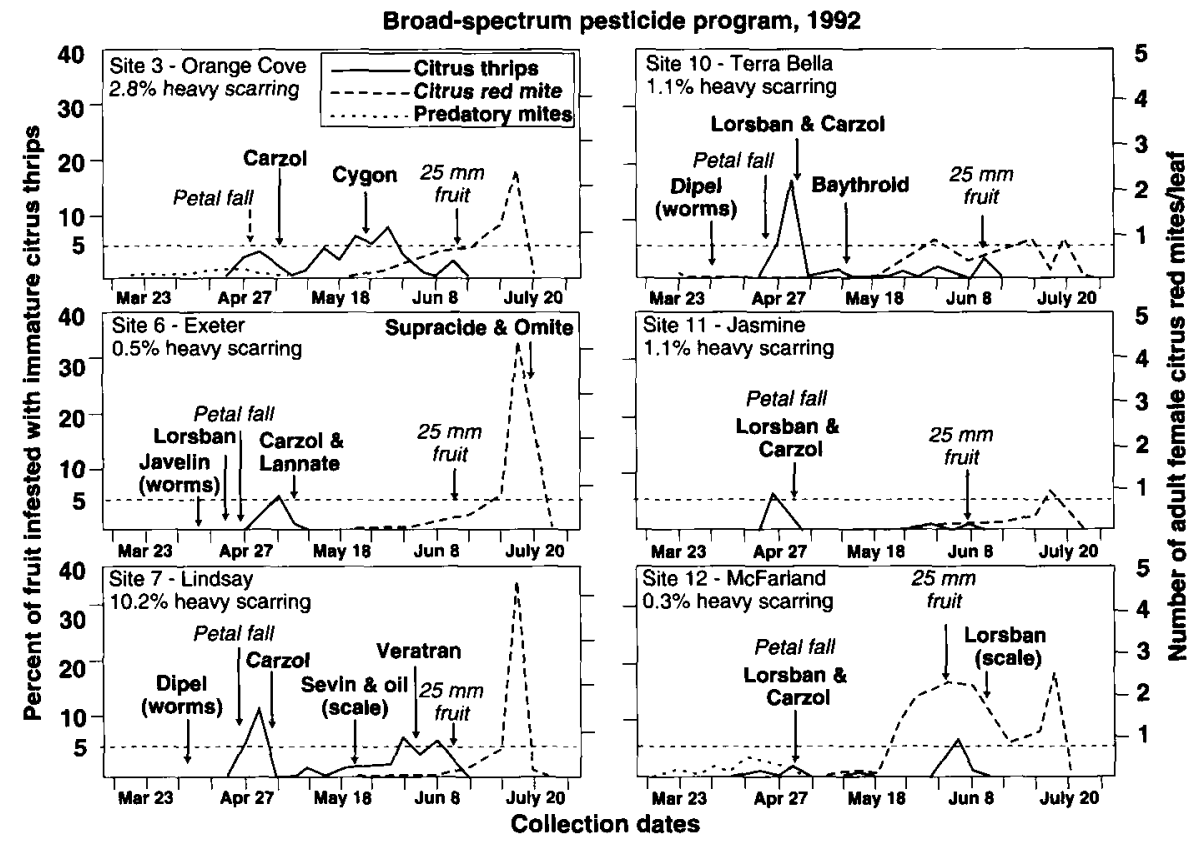

Fig. 1. Citrus thrips, citrus red mite and predatory mite population densities in the six orchards initially treated with broad-spectrum pesticides in 1992.

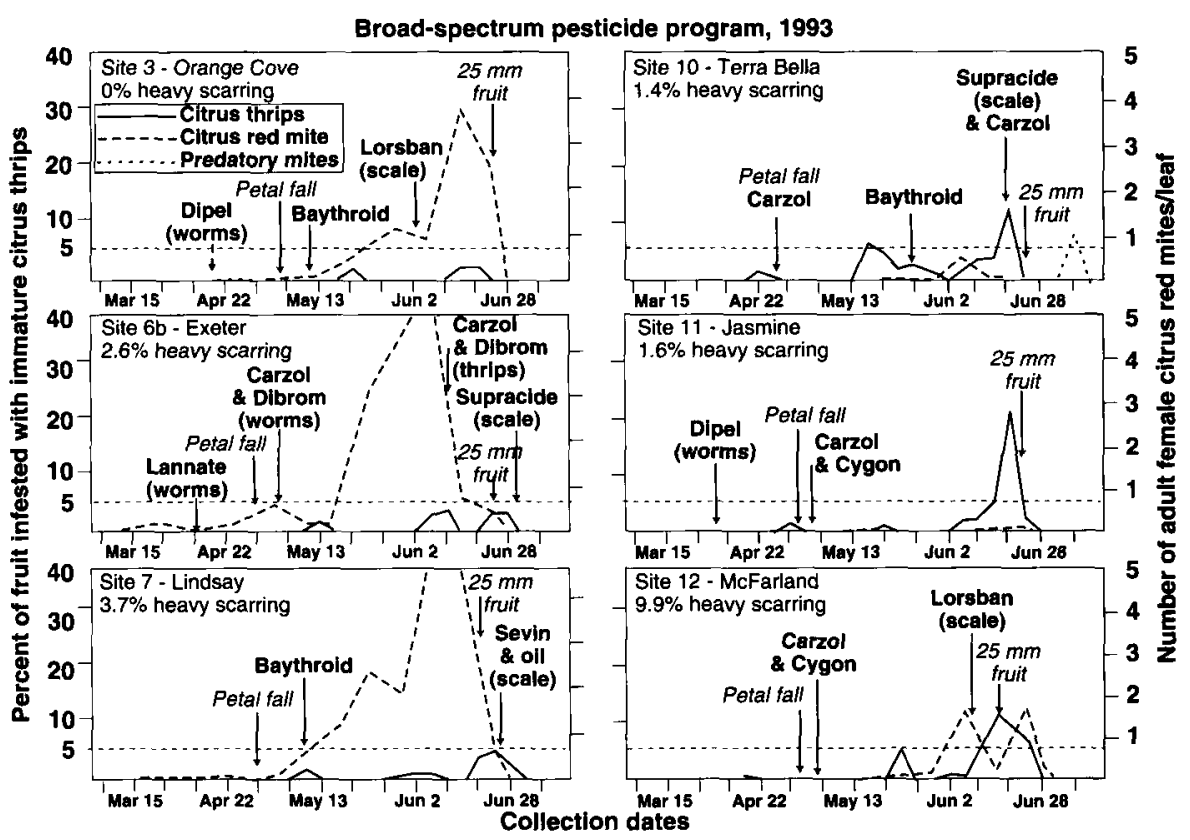

Fig. 2. Citrus thrips, citrus red mite and predatory mite population densities in the six orchards treated with broad-spectrum pesticides in 1993. Sites $3,7,10,11$ and 12 were the same orchards sampled in 1992.

remained low for the rest of the season (fig. 1). The citrus thrips in these two sites did not exhibit any signs of resistance. In Sites 3, 7 and 12, citrus thrips populations increased to treatable levels 2 to 4 weeks after the initial control experienced with the post-petal fall applications of Carzol and Cygon, and additional pesticide applications were necessary. treatment in Site 7 for citrus thrips control. An application of Baythroid was made in Site 10; however, there were few immature citrus thrips on the fruit and so this application may not have been warranted.

Figure 2 shows the densities of citrus thrips, citrus red mite and predatory mites in the orchards using a broad-spectrum pesticide program during 1993. In that year, citrus thrips did not appear in significant numbers until several weeks after petal fall (April 29 to May 1, 1993). In spite of the fact that citrus thrips densities were low, all of the growers applied Baythroid, Carzol or a Carzol/Cygon combination an average of 4.5 days after petal fall. This indicates that PCAs and growers who use the broad-spectrum pesticide program tend to apply citrus thrips pesticide sprays based on a calendar schedule (immediately after petal fall) rather than using the UC IPM threshold treatment level. Growers rationalize using the calendar spray method because they can't get their spray equipment to all of the orchards in the short period of time during which citrus thrips populations develop. However, there are consequences to spraying before citrus thrips are detected or when their populations are very low. The first poorly timed spray application may select for resistance in the citrus thrips, so that later sprays are even less effective.

Predatory mite densities were undetectable or were reduced to this level after the first spray was applied in the sites where broad-spectrum organophosphate and carbamate insecticides were used just after petal fall (figs. 1 and 2). Predatory mites were very sensitive to field rates of these insecticides and thus did not assist with citrus thrips control in these sites.

We examined the fruit for scarring due to citrus thrips in late September of 1992 (fig. 1). Sites 6, 10, 11 and 12, in which thrips populations were low throughout most of the susceptible period of the fruit, sustained $1.1 \%$ or less severe scarring of fruit by thrips. In the two sites in which immature thrips populations on fruit approached the threshold of 5 to $10 \%$ infestation during most of the susceptible period (petal fall through 25-mm fruit size), higher se- 


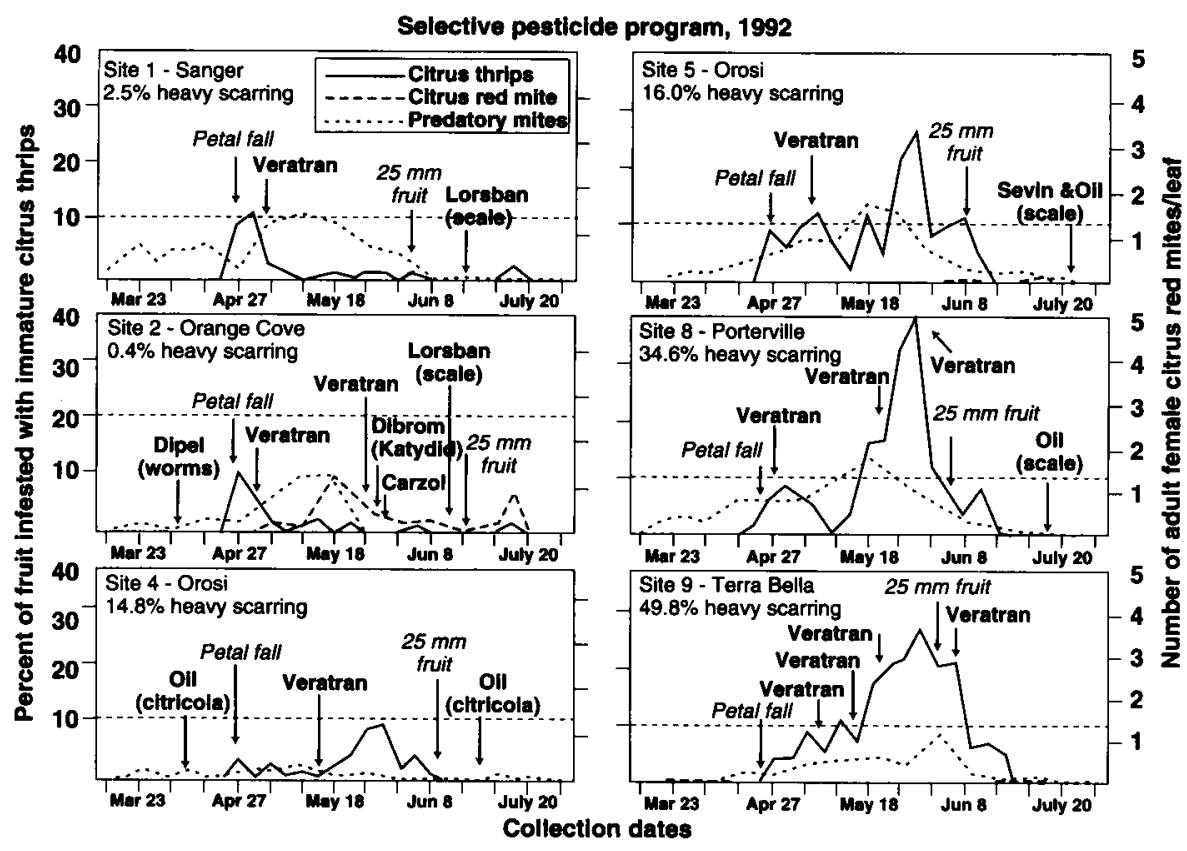

Fig. 3. Citrus thrips, citrus red mite and predatory mite population densities in the six orchards initially treated with selective pesticides in 1992.

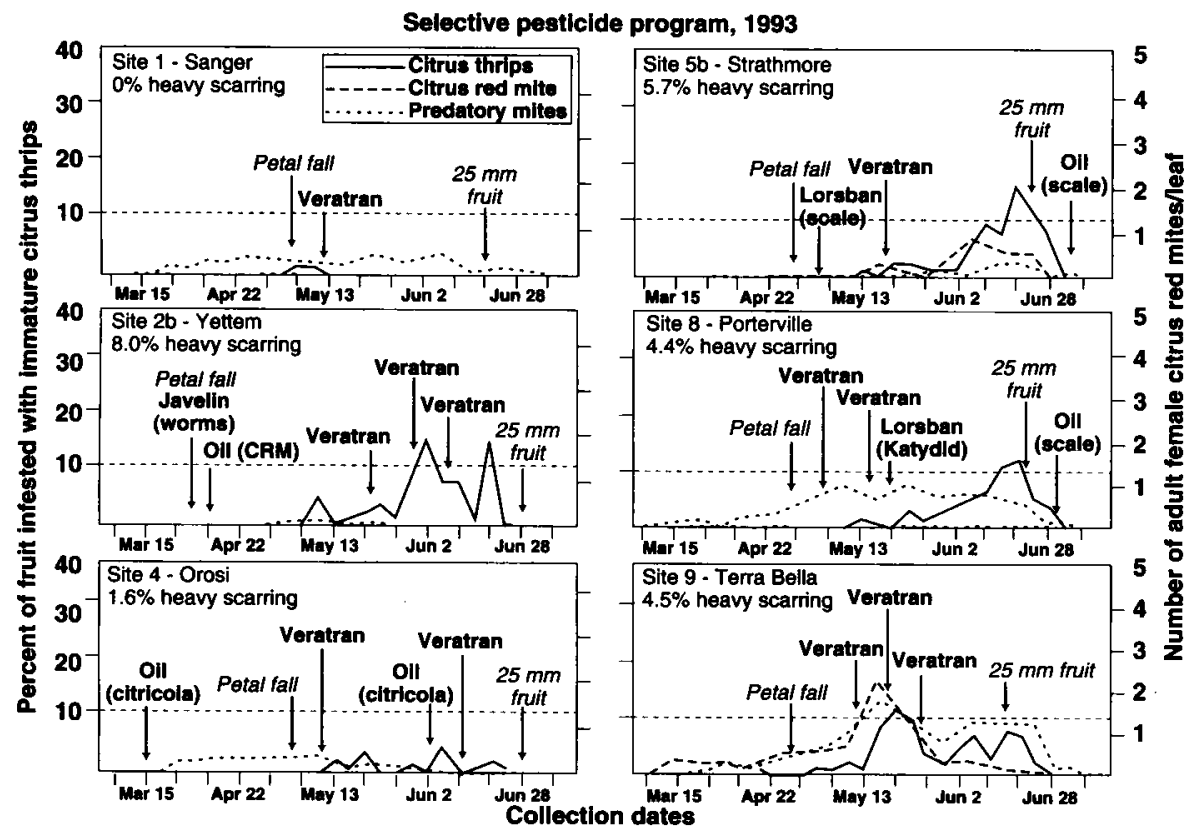

Fig. 4. Citrus thrips, citrus red mite and predatory mite population densities in the six orchards initially treated with selective pesticides in 1993. Sites 1, 4, 8 and 9 were the same orchards sampled in 1992.

vere fruit damage was sustained $-2.8 \%$ in Site 3 and $10.2 \%$ in Site 7.

In 1993 citrus thrips populations in several of the sites did not build up to damaging levels until the fruit reached $25 \mathrm{~mm}$ in size and was no longer susceptible to injury (fig. 2). In Sites 3, 6b and 7 , citrus thrips populations remained below the $5 \%$ infested fruit level throughout the susceptible pe-
Citrus red mite populations increased dramatically in late May to levels ranging from 0.8 to 6.0 adult female mites per leaf in 11 of the 12 sites where broad-spectrum pesticides were applied (figs. 1 and 2).

These levels of citrus red mite were below the treatment threshold of 8 adult female mites per leaf established in the UC IPM guidelines (UC IPM Publications 15 and 3303). However, these data demonstrate that broadspectrum pesticide use aggravated citrus red mite populations. This may be because broad-spectrum pesticides eliminated the predatory mites and other natural enemies that feed on citrus red mite; or they may have stimulated reproduction of the citrus red mite. Citrus red mite populations declined rapidly in late July or early August, probably due to a combination of high temperatures and a virus epidemic. In Site 6 (1992), the grower applied the miticide Omite with the organophosphate scale spray Supracide to help control mites. However, the miticide treatment was probably not needed, since untreated mite populations declined dramatically at that time of year.

\section{Selective pesticide approach}

Figure 3 shows the densities of citrus thrips, predatory mites and citrus red mite in the six orchards that were started with a selective program of Veratran for citrus thrips control in 1992. As in the broad-spectrum orchard program, immature citrus thrips emerged on the fruit in high numbers immediately after petal fall in late April of 1992. Based on UC IPM Publication 15 and 3303 recommendations, the treatment threshold for navels is $10 \%$ of fruit infested with immature citrus thrips when more than 0.2 predatory mites per leaf are present. The threshold for Valencias (20\% of fruit infested) seen in Site 2 is higher than the threshold for navels because Valencias are not as easily damaged. Five of the six selective program sites had predatory mite densities greater than 1.0 mites per leaf. Generally, 1 to 3 years after growers stop using organophosphate and carbamate insecticides on citrus, the predatory mites 
and other natural enemies increase. The treatment thresholds for citrus thrips infestation were reached early in the 1992 field season in Sites 1, 5, 8 and 9 .

In Sites 1 and 2, predatory mite densities reached nearly 1.5 mites per leaf, and a single application of Veratran was made just after petal fall. Citrus thrips densities on fruit remained low in these sites through the rest of the season, and only $2.5 \%$ (Site 1) and $0.4 \%$ (Site 2) heavy scarring of fruit was found at the end of the season. This suggests that Veratran in combination with predatory mites and other natural enemies can control citrus thrips populations. In Site 2, Dibrom was applied for katydid control and Carzol was applied for an additional citrus thrips treatment. However, the citrus thrips population was very low at the time of the Carzol spray and so this spray was probably unnecessary. The Dibrom and/or Carzol reduced the predatory mite population to undetectable levels.

In Site 4, the citrus thrips densities were relatively low until late in the season. Two Narrow Range 415 petroleum oil treatments were applied in this site for citricola scale control. These oil applications suppressed the predatory mite densities to below 0.5 per leaf and aggravated the citrus thrips population, resulting in $14.8 \%$ scarring of fruit. Sites 5, 8 and 9 experienced very high citrus thrips populations throughout the period of fruit susceptibility. These orchards had predatory mite densities ranging from 1.3 to 1.7 mites per leaf, and growers made one to four applications of Veratran. However, these two control methods together could not sufficiently reduce citrus thrips populations, and heavy fruit scarring ranged from 16.0 to $49.8 \%$.

There are many possible reasons why the Veratran and predatory mites did not successfully control citrus thrips in Sites 5, 8 and 9 in 1992. It has been observed in some orchards that citrus thrips populations flare up when growers shift from broad-spectrum to selective pesticides. This is because natural enemies are rare and require time to build up during the first year after broad-spectrum pesticide use is halted. Also, citrus thrips have been shown to reproduce to a greater extent when exposed to low dosages of some pesticides.

Another factor influencing the efficacy of a Veratran program is timing of the application. Veratran is a stomach poison, and must be ingested by the citrus thrips to poison them. It is most effective when applied when the citrus thrips population is composed primarily of feeding immature thrips, and its toxic effect does not last very long. Site 9 had received broad-spectrum pesticides the previous season, the timing of the 1992 application appears to have been late, and it rained immediately after the Veratran was first applied in 1992. This combination of problems resulted in poor efficacy of the insecticide. In Sites 5 and 8, growers had been using selective pesticides for several years and did not have severe citrus thrips damage in the years preceding 1992. It is likely that the high citrus thrips population in these sites is a product of factors that we do not yet fully understand. PCAs have observed that some orchards in the San Joaquin Valley simply have greater citrus thrips pressures than others and so may not be predictably controlled by Veratran and predatory mites.

Figure 4 shows the mite and citrus thrips populations in the selective pesticide program orchards during 1993. The citrus thrips populations did not develop into significant populations in these sites until 2 to 4 weeks after petal fall. It is interesting to note that in a year when citrus thrips populations developed late in the season, growers who used the selective program tended to wait an average of 7 days longer than those in the broad-spectrum pesticide program before applying their citrus thrips treatments. This is because PCAs are aware that Veratran has a very short residual action and it must be applied when thrips are actively feeding.

Sites 1 and 4 had one and two treatments of Veratran and very low densities of thrips, and sustained $0 \%$ and $1.6 \%$ heavy scarring of fruit, respectively. Sites $2 b, 5 b, 8$ and 9 had greater-than-threshold densities of cit-

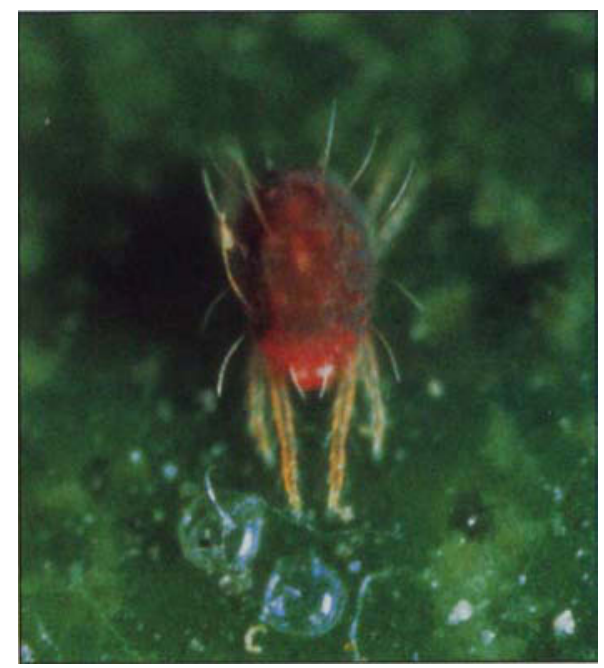

Feeding by citrus red mite in the early season causes the fruit and leaves to become stippled or silvered. These symptoms usually disappear as the fruit matures.

rus thrips for several sampling periods and sustained 4.4 to $8.0 \%$ heavy scarring. Sites 8 and 9 had higher levels of predatory mites ( 0.5 to 1.0 per leaf) and suffered less heavy scarring than sites $2 b$ and $5 b$. This suggests that predatory mites contribute to citrus thrips control. Oil treatments were applied to Sites $2 b$ and Site 4 for citrus red mite and citricola control, and these oil treatments suppressed predatory mite densities to below 0.2 per leaf.

Figure 3 shows that in 1992, 34.6\% and $49.8 \%$ heavy scarring was found in Sites 8 and 9 respectively. However, in 1993 (fig. 4) these same orchards experienced only $4.4 \%$ and $4.5 \%$ heavy scarring. Thus it may be more difficult in some years than in others to control citrus thrips with a Veratran and natural enemy program.

In the orchards treated with selective pesticides in 1992 (fig. 3) and 1993 (fig. 4), citrus red mite increased to detectable levels in only 3 orchards out of 12 , with peak densities ranging from 1.0 to 3.0 female mites per leaf. This is in contrast to the broad spectrum sites (figs. 1 and 2), in which citrus red mite populations developed in 11 out of 12 orchards after the citrus thrips treatments were applied, with densities ranging from 0.5 to 6.0 females per leaf. Thus a program of selective pesticides reduces the risk of serious citrus red mite infestations and 
